tegrate of the $P$. formosa genome, it is doubtful whether this phenomenon is strong enough to counteract Muller's ratchet. It seems likely that only one or a few parts (regions close to a centromere) of the black molly genome can be incorporated into heritable microchromosomes. Otherwise, one would expect high frequencies of different microchromosomes in the laboratory population, which is not the case. Therefore, the number of genes that can be revitalized seems limited.

Schartl et al. also argue that paternal leakage into an asexual strain offers a genetic advantage to the heterospecific males. However, this is only true when the asexual and sexual strains exchange genes in both directions. In this system, however, $P$. formosa females are an evolutionary dead-end: their genes are never transmitted back into the host species. As a result, males that mate with $P$. formosa cannot enjoy increased fitness in their

\section{Community response to IRONEX}

SIR - The iron fertilization experiment in the sea near the Galapagos Islands in midOctober 1993 (IRONEX) $^{1}$ showed that the cell division rate of unenclosed phytoplankton, initially high, was quickly enhanced by $\mathrm{Fe}$ addition, as had been found in bottle experiments in other high nutrient (nitrate)-low chlorophyll regions. However, the increase of phytoplankton concentration during the days after the IRONEX experiment was not merely an issue of cell physiology ${ }^{2}$, but was a system response resulting in a new balance between cell division rate and losses from grazing and physical factors. I suggest that even for the first 3 days after fertilization (days 299-301) the grazers continued to keep this offshore phytoplankton in check despite the increase in the rates of photosynthesis and cell division. In addition, the remineralization of carbon by the food web during this time helps to explain the small effect of the iron enrichment on the $\mathrm{CO}_{2}$ system ${ }^{3}$.

The grazing loss, not measured during IRONEX, is calculated here for the upper $\sim 20 \mathrm{~m}$ during the first 3 days after fertilization, using estimates of photosynthesis (from ${ }^{14} \mathrm{C}$ uptake over $24 \mathrm{~h}$ starting within $1 \mathrm{~h}$ of local noon; Fig. 3 of ref. 1) and change of phytoplankton biomass (from microscopy: $\mathrm{C}$ values kindly supplied by K. Buck, K. J. Coale and S. J. Tanner). The near-constant concentrations of the inert tracer $\mathrm{SF}_{6}$, added to the Fe-enriched water (column 6 of table; values kindly provided by A. J. Watson), show that losses of phytoplankton from physical dilution were negligible. Also, sinking of the dominant small cells ${ }^{1}$ can be discounted.

Using the ${ }^{14} \mathrm{C}$ uptake data during the 3 days as a measure of particulate own species and therefore cannot be selectively rewarded for their genetic contribution to the asexuals.

We do not disagree with the possibility of occasional introgression of paternal characters into $P$. formosa: this has already been suggested by Haskins et al. ${ }^{2}$. It would explain why $P$. formosa, as well as other gynogenetic fish ${ }^{3,4}$, are more genetically diverse, as would be expected for clonal animals. Yet the data do not allow Schartl et al. to conclude that the Amazon molly can escape Muller's ratchet.

Leo W. Beukeboom, Rolf P. Weinzierl Nico K. Michiels

Arbeitsgruppe Michiels, Max-Planck-Institut für Verhaltensphysiologie,

D-82319 Seewiesen, Germany

1. Schartl, M. et al. Nature 373, 68-71 (1995)

. Haskins, C.P. Haskins, E.F. \& Hewitt, R.E. Evolution 14 $473-483(1960)$

Vrijenhoek, R.C. Am. Zool. 19, 787-797 (1979)

4. Moore, W.S. in Evolutionary Genetics of Fishes (ed. Turner, B.J.) 329-398 (Plenum, New York, 1984).

dynamics of the microzooplankton continued to be tightly controlled by their predators, and so the only lasting biomass increase from growth due to the fertilization was probably among the larger zooplankton. Such an increase, without a change in chlorophyll concentration, is clearly seen in the seasonal studies in the high nutrient-low chlorophyll subarctic Pacific, when during the late spring and summer the light-limitation of the phytoplankton is removed ${ }^{4}$. This biomass increase would have been difficult to measure during the IRONEX cruise.

Also, elsewhere in the open, undisturbed eastern equatorial Pacific, the phytoplankton population dynamics are understood to be controlled by grazing in an Fe-limited ecosystem ${ }^{5,6}$; the grazing remineralizes iron, which is immediately taken up by the phytoplankton ${ }^{7}$. Obviously, a balance of rates of cell division and mortality (grazing) alone cannot maintain the observed temporal and regional stability of phytoplankton concentrations. Because the high cell division rates (estimated to have been 1.0 per day initially and 1.5 per day on day 301$)^{1}$ show that iron supply did not markedly constrain the phytoplankton physiology, stabilizing factor(s) such as feeding threshold and a low half-saturation constant of the grazing response $^{8}$ must have led to a new equilibrium differing surprisingly little from that in the ambient waters.

In conclusion, considering the zooplankton-caused limits as the proximate control of phytoplankton concentrations during IRONEX is profoundly different from referring to phytoplankton physiolo$g y^{2}$ or the carrying capacity of the system limited by settling of particulate Fe (ref. 1). The algal population dynamics at the IRONEX station on the Galapagos shelf ${ }^{1}$, however, behaves differently from populations in the open sea. I believe one reason to be the Fe-induced larger size of the cells and the ensuing problems for the grazers, just as on any other shelf where there are phytoplankton blooms.

\section{Karl Banse}

School of Oceanography,

University of Washington, Box 357940 ,

Seattle, Washington 98195, USA

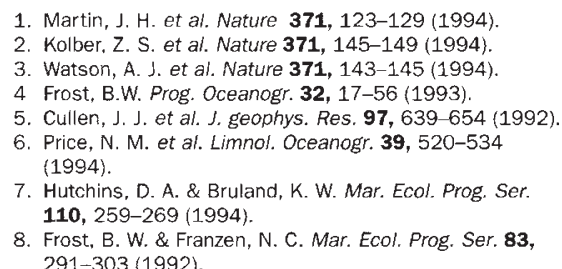

8. Frost, B. W. \& Franzen, N. C. Mar. Ecol. Prog. Ser. 83, 291-303 (1992). ization, starting at day 299. Column 3, initial photosynthesis from outside the fertilized patch (equivalent to "out" in Fig. 3 of ref. 1), $\mu g$ $C$ per I per day. Column 4, phytoplankton in $\mu g$ C per I; column 5, C lost, difference between the $\mathrm{C}$ uptake during the preceding $24 \mathrm{~h}$ (3rd column from left) and the change in concentration during the same interval (from col. 4). Column $6, \mathrm{SF}_{6}, 10^{-14} \mathrm{M}$ in the fertilized water, the ambient being less than $10^{-15} \mathrm{M}$.

\section{Scientific Correspondence}

Scientific Correspondence is intended to provide a forum in which readers may raise points of a scientific character. Priority will be given to letters of fewer than 500 words and five references. 